\title{
The Influence of the Facebook Social Network in Electronic Business and Costumers' Online Security
}

\author{
Kastriot Blakaj PhD (c). \\ Teaching Assistant - Computer Sciences - European College Dukagjini
}

Doi:10.5901/ajis.2014.v3n2p205

\begin{abstract}
Social network websites became very popular nowadays. Facebook social network website became an important part of culture that exists within the society. The intention of this study is to identify and analyze the role of social media in the prectices of electronic business and electronic marketing. Especially the use of social network Facebook for practices of electronic marketing of organizations and security of online consumers. There is a tension between the lucrative sides of business in social network websies, where many profits can be gained through marketing in social networks and thus different companies choose a basic level of security for their costumers. There will be different phases to expain the role of social Medias and its influence in development and promotion of online products. Analysis have been made on a literature and a case study in order to create new ideas that the research has to do with about previous inquiries and check if the assumptions are feasible in some of the companies that use facebook social network for e-marketing. The research results showed that using social media increases the ability of the business and the performance of the business, different means of social media and information technology shall be able to be used in almost all different stages of the value and increase of productivity in the enterprice. Online privacy problems that follow leaks from the fact those individuals are careless that an amount of relevant identifyable information were offered to an undetermined number of people.
\end{abstract}

Keywords: Social networks, Facebook, e-marketing, e-business, online security

\section{Introduction}

The subjet that we will explain is "the influence of social networks in electronic business and e- marketing), a general entry in relation to internet and social networks, what is SMM? (Social media marketing), how marketing is done in social network, who are the social networks where marketing can be made?, which are the mos concurrent networks or most frequented one and the favorable for marketing.

In recent years the technology had a huge momentum in development. The development in this area was foreseen long time ago and its massive influence on people

You just pay attention during a single day of you life of how many people use social networks, now possible in their smart phones. We have access in social networks whether in cafeteria, in a meeting, a beautiful day in a park or even at the house where you are a guest.

The technology is everywhere and with it in social networks. From a research done by "Për Internet", in August 2012 , it is found that $69 \%$ of adults worldwide are connected to social networks, whereas in the research of the author of the work it is found that in Kosovo Facebook is used about $71 \%$, regular users, whereas $29 \%$ are evarage users. Some of the mostly used social networks by people are Facebook, Linkedln, Twitter, YouTube, Pinterest, Instagram, Tumblr and many other blogs. Imagine if you would have a business where you would like to advertise different offers, one of the best ways, most efficient and the most used in recent times is marketing through social networks.

\section{The use in different stages at business process}

Different business models are designed to remember all different activities that a business does.

There different models os business that illustrate processes or completed activities by the organizations where social media activities can be integrated, i.e. the known frame 7S of McKinsey (Peter \& Waterman, 1982), at Canvas Business Model of OSTERWALDER and Pigneur (2010) or Value Chain of Porter ( 1985), created the international framework of the models of online business.

This document makes the use of chain value of Michael Porter (1985) to illustrate how social media can be used in 
a business process and activity.

The chain of the value includes more elements of business process that makes it more a as whole. Therefore, the chain of values shall be an appropriate model jetë model of business to explain the use of social medias in different activities od B2B (business to business).

\subsection{Marketing and Sales}

Another main activity of the chain value is accompanied with sales marketing. The activities of marketing and sales are disturbed to make costumers aware about products or services that they offer. Examples of marketing and sales activities are the selection of the preferred channel of costumers, advertisements, promotion and sales. The consumers can be informed about a product or service by using different social media channels, i.e. social network websites, blogs, and internet websites of corporations. Organizations should spread information to their clients regarding their products andservices, except that, blogs and websites if social networks can be used to see how much success they have on online sales.

Some of known companies that offer online services and information in Kosovo and wider.

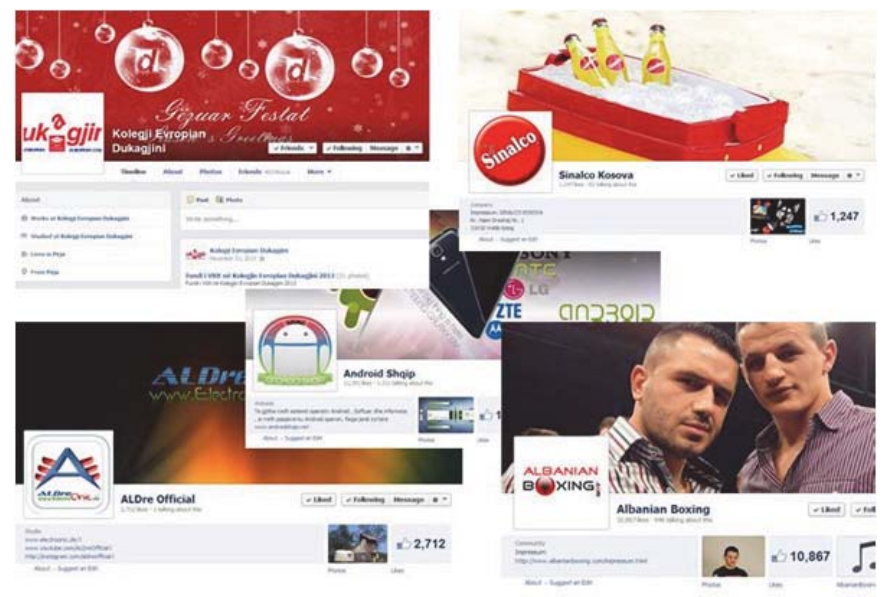

\subsection{Types of consumers and Digital Media}

While digital marketing created wonderful opportunities for companies to interact with their clients, digital media are more of delayed consume than traditional media. The internet users have the possibility to read the content of the Enterprice and decide from homeabout the product that they like.

Two factors ignited the increase of consumers' information:

1. The cosnumers tendency to publish their opinions, coments and discussion about products through blogs and digital media has increased.

2. The consumer tendency on corporations. The consumers often rely on recomandations from friends, families and other consumers when they decide for buying.

The types of digital media where internet users take part include social networks, blogs, wikis, video sharing pages, podcast.

\subsection{Social networks}

Social networks (social media) are phrases that are heard enough, however what are they how do people understand them? What kind of influence do they have in their life and what is their importance? If we say that skype is a social media and youtube is a social media how we can determinate social media? The word media has a meaning of a type of communication instrument and a communication of news, social media are communication instruments. Some of the social media are: facebook, twitter, linkeding, and blogs. Facebook leads, then after it twitter etc. 
The scheme of using social networks:

During the search of the data for using social media in New Zeland. New Zeland has the highest scae of social network use in the world.

Fig.1 Shows which media are the most used social network

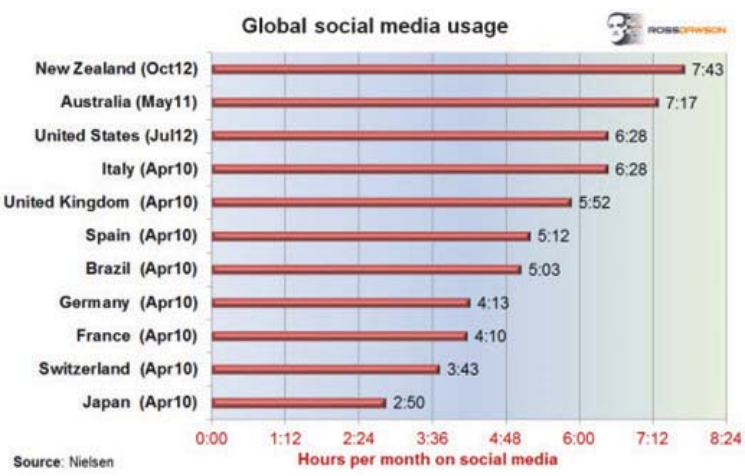

Source:http://rossdawsonblog.com/weblog/archives/2013/02/analysis-us-australia-social-network-usage-flat-newzealand -now-the-worlds-biggest-user-of-social-networks.html

The above diagram shows a summary of data from Nielsen, time spent per month in social networks in a series of countries of the world.

Fig.2 Shows which are the most used social networks

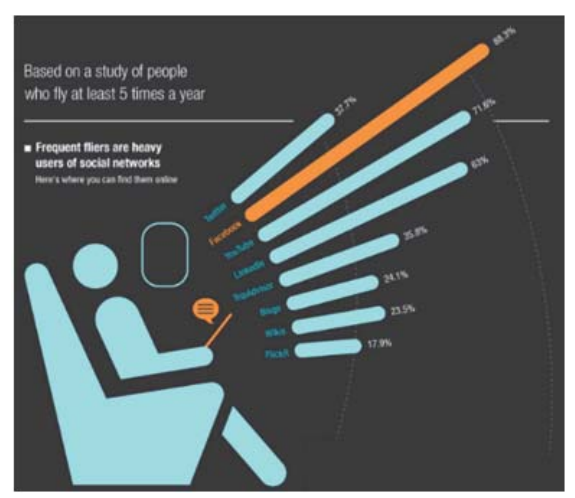

Source: http://lightspandigital.com/blog/social-media-statistics-roundup-professional-social-networks-and-more-linkedin

Social media are used by different ages starting from school ages, adolescents, adults, and old people. The most trusted users' adolescents who want to move ahead with time. As it is known social media are mostly used for communication for sharing opinions, pictures, outputs etc. some of adolescents dependant on social media more than other age groups.

\section{Privacy platform}

Applications give the possibility to third prties to have acces on the data of the users that otherwise would not be possible for the developers through the inpage of the user. The pages of social networks allow acces to third parties on user information which install directly any application. The users cannot add any application to their profile without giving users acces if second degree. Then the application developers can see the user data that otherwise would not be possible if they are not friends with users. Otherwise from regular social relations it is also simetrical but not transparent, the user 
cannot know on whise ownership the application is. Current situation regarding privacy (installed or not), that induces users to give access to data, that can be not necessary. Table 1 shows data for 150 applications categorized in "foreign" - is referred to persons that use applications, "friends" and "foreigners" from their relation they can follow that person.

Table 1. The data for 150 aplications

\begin{tabular}{||c|c|c|}
\hline \multicolumn{2}{|c|}{ Information used } & Applications \\
\hline \multirow{3}{*}{ Public } & None & $13(8.7 \%)$ \\
\cline { 2 - 3 } & Foreigners & $113(88.7 \%)$ \\
\cline { 2 - 3 } & Friends & $99(66.0 \%)$ \\
\cline { 2 - 3 } & Foreigners & $51(34.0 \%)$ \\
\cline { 2 - 3 } & All & $133(88.7 \%)$ \\
\hline \multirow{3}{*}{ Private } & Foreigners & $12(8.0 \%)$ \\
\cline { 2 - 3 } & Friends & $10(6.7 \%)$ \\
\cline { 2 - 3 } & Foreigners & $7(4.6 \%)$ \\
\cline { 2 - 3 } & All & $14(9.3 \%)$ \\
\hline
\end{tabular}

Source: Computational Social Networks: Security and Privacy, 2012.

\subsection{Analysis of the attacks in social networks}

Clear diagrams from social networks through nicknames are incomplete since the aspects of graphical structures are discovered and can be used to show the identity of the persons. In a simple attack diagram, the attacker finds himself by beign the first user by being the first user to install the application. Then the attacker can compare the lists of friends from each of his friends with his by searching for different models. This type of attack is quite limited and this way the identification can be initiated only when the joint that is around the structure is known.

The attacks that rely on known data from internet intercommunicate "faces" with the same limitations. By connecting the true structure and anonymous structural diagrams they ask for knowledge of the true structure.

The intention and the assumption are inappropriate for the privacy model in the social network sites. The intention of the attacker in this model is to start with social diagram and by connecting it with a huge number of real users, as it is supposed to be started with a small joints number and by trying to find them in the diagram. The relationship actually can't be used to have an attack in the mentioned model, because the attacker that can be our friend together with users that intends can take the attack in unnecessary manner by obtaining the direct acces in their data through Web. Because the friends' lists are not directed, they cannot be used further, in this case if the attacker is dealing with user tools, then the attacker has access in their profiles.

\subsection{Public data in social networks}

Some information is thought to be public with the intention of identification of the user and public data are presented with same characteristics. As example, anartificaial obstacle is placed on public information about personal identification in order to prevent any possible abuse. This obstacle is necessary to prevent the attack where the application developer install the application in their accounts and it is tried to use in order to learn the compilation coded ID's of applications and true user ID's. In this arbitrary way public information shall appear, the attacker can create a special page that consists of a long list of IDs'.

The fight of attack against public data is done by limiting the possibility of applications to show public information of only those IDs' $\mathrm{n}$ in contact with the current list of users, which is a new structure maintained in the sites of social networks. The contact lists are distinguishable from other types of contact lists from other social network sites. They prevent different attacks to see the user names by allowing the other users to see only public names with which they have any certain relation.

\subsection{Validity of data and their identification}

The conditions of the services in a site encourage users to publish profiles that are directly linked to with them and not other entities, people or fictive characters. Furthermore, in order for the users to become members of Facebook social 
network an active e-mail address should be offered. This request, together with the vision of organizing of real life of social sites for their members offers stimulation for users that only publish necessary information.

In general, determination of information accurary that are used by Facebook users is not small for all not just for certain cases.

Profile names - In manual manner Facebook profile names are categorized which could be as below:

- Real names (names that appear as true ones),

- Partial names (only the name is given),

- Not real name (in a clear manner it is an untrue name).

Source: Abraham Ajith, Computational Social Networks: Security and Privacy, Seattle, 2012, page 102.

Table 2 offers results of an assesmend made. As a sample 100 Facebook names were taken from facebook. It is found that $89 \%$ of all names are true for the users compared to only $8 \%$ of names that are not true. The percentage of users that choose to display only the name is very small, about $3 \%$. With another words, the most of the Facebook users offer full identifyable names, which are not obliged to do so.

Table 2. Categorization of names based on quality

\begin{tabular}{|c|c|}
\hline Category & Percentage of Facebook profiles \\
\hline Real names & $89 \%$ \\
\hline Partial names & $3 \%$ \\
\hline False names & $8 \%$ \\
\hline
\end{tabular}

Source: Computational Social Networks: Security and Privacy, 2012.

As a comparison, $98.5 \%$ of profiles that include the date of birth offer the full date of birth (the day, month, and year), however, they are not obliged to do so, so that the information are complete. The evaluation of the validity of the birth dates is not unimportant. However, in certain circumstances friends from the friesnds list should be observed while they post wishes for their birthdays in the comments sector od user profile on the day that it is reported from the user as his her birthday..

\section{Case-Study Customer Questionnaire}
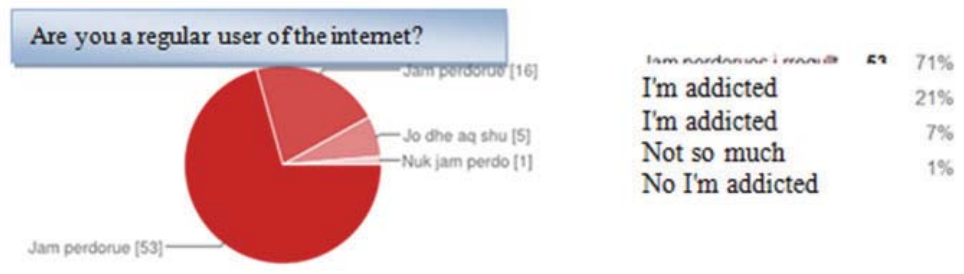

Fig.3. Internet Usage

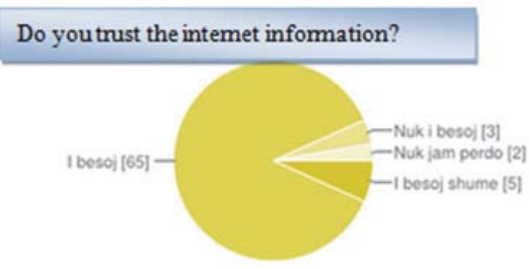

$\begin{array}{lrr}\quad \text { Inocnichume } & \text { 6 } & 7 \% \\ \text { I believe more } & & 87 \% \\ \text { I believe } & & 4 \% \\ \text { Distrust } & & 3 \% \\ \text { No I'm addicted } & \end{array}$

Fig.4 Percentage of credibility of Internet information 


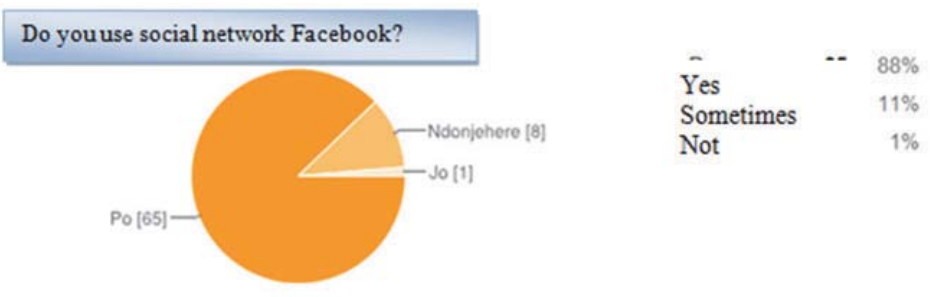

Fig.5. Usage of social network Facebook
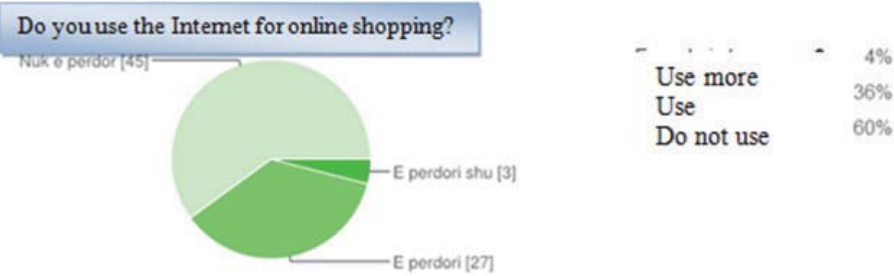

Fig.6. Using the Internet for Online Shopping

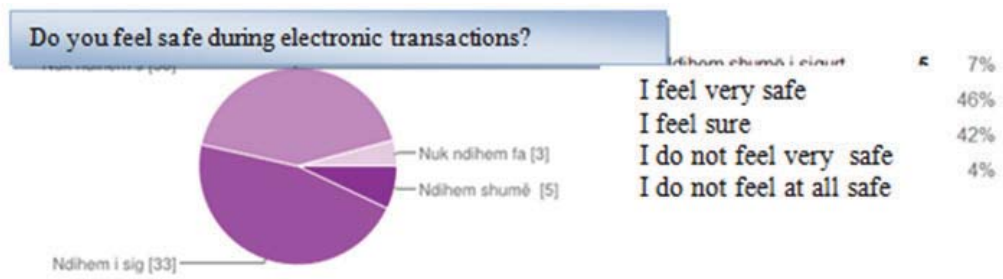

Fig.7. Security during transactions

\section{Conclusion}

Social network sites, among them Facebook social network are very much usable because a user can be connected with any other person in any part of the world. Internet as a tool has revolutionized the world. A person can talk to another person by the help of social network sites. Usualy individuals connect in social networks with people that they know or family related. Privacy s question is very essential when a user uses social networks for daily work. Forthermore the privacy is so essential that social network sites have tendency to be misused.

Privacy or the little secret in social network Facebook acts as a security tool. There can be cases when someone tries to displace important information from one user account without the approval of the user. In such cases the privacy tool in social network sites becomes the main priority.

Unauthorized person may have access on basic information of a user like personal data and pictures. There are new types of crime like cyber crimes that steal very important information from user accounts and use them for personal gains.

The user should have bigger care while he posts information about himself in Facebook social network. Information like bank account, date of birth and any other information should not be exposed in social network. Relevant information and other details about personal life should not be given to social networks. Great care should be paid when installing foreign applications to your facebook account. Outside applications are created by groups or unknown parties and do not have any previous relation with you facebook account. Another great obstacle that outside applications appear is the lack of privacy tool. The password of your account in facebook social network should be different from your personal email. As a consequence of that there will be more privacy and security for the user. Another fundamental thing is the need to keep in mind that private information that is given in facebook for online marketing may not be private information. The user 
should be very careful while he works in social network.

Basic elements that show the efficiency of the system are:

1. the intention is presentation and real overview of them in society, business or individual.

2. What service do they propose ans their overview in the website?,

3. It should be understood that without having the two first onesit is impossible to function, so they should have a way of commanding / purchase/ subscription in their website.

4. In order ti have online marketing there should be real online activitynof the said company (or at least the online existence), otherwise there is no meaning.

As a result we can say that the problem comes form the societies or marketing teams of a certain company. If companies, businesses, or individuals here, do not manage to understand the importance of online marketing or to advance the concept of online selling, online marketing Albania and Kosovo will never see the glance that other countries have.

\section{References}

Grupautoresh për ECDL (European Computer Driving Licence), Smart Bits, Prishtinë, Shtator 2005.

Beqiri, Dr. Edmond: Interneti- komunikimet kompjuterike, Prishtinë, 2000

Rrjetin Interaktiv për Arsim dhe Burime RRIAB, "Grupautoresh për stërvitjen e arsimtarëve të shkollave fillore për përvetësimin e njohurive dhe shkathtësive elementare për zbatimin e teknologjisë së informatikës", Shkup.

Kim, W., Jeong, O., \& Lee, S. (2010), On Social Web sites, Information Systems.

Ladner, R. E. (2008). Soft computing techniques for web service brokering. Soft Computing.

Lai, L. S.-I. (2010). Social Commerce - E-Commerce in Social Media Context. World Academy of Science, Engineering and Technology. Lu, Y., Zhao, L., \& Wang, B. (2010). From virtual communities members to C2C e-commerce buyers: Trust in virtual communities and its effect on consumers' purchase attention. Electornic Commerce Research and Applications, 9(4), 346-360.

Mayer, A. (2009). Online social networks in economics. Decision Support Systems, 47.

Prell Christina, Social Network Analysis: History and Methodology, London, 2011.

Abraham Ajith, Computational Social Networks: Security and Privacy, Seattle, 2012.

The Business Impacts of Social Networking (Ed.)^(Eds.). (2008). AT\&T.

Andam, Z. R. B. (Ed.) (2003). The e-ASEAN Task Force and the UNDP Asia Pacific Development Information Program (UNDP-APDIP).

Benjamin, P. and Elsie, O. (2003), "The impact of electronic commerce on procurement", Journal of Organizational Computing and Electronic Commerce, Vol. 13 Nos 3/4, pp. 167-89. Cloete, E., Courtney, S. and Fintz, J. (2002), "Small businesses' acceptance and adoption of e-commerce in the western-cape province of South-Africa", Electronic Journal on Information Systems in Developing Countries, Vol. 10 No. 4.

Cod, C. (2011). 5 Big Advantages to Social Marketing. Retrieved November 25, 2011, from http://www.you-andme.hubpages.com/hub/5-Big Advantages-to-Social-Marketing

Aggarwal C. Charu, Social Network Data Analytics, New York, 2011.

Russell A. Matthew, Mining the Social Web: Analyzing Data from Facebook, Twitter, Linkedln, and Other Social Media Sites, 2011, USA.

\section{Internet Soruce}

http://www.facebook.com

http://www.wikipedia.org

http://www.howstuffworks.com

http://www.wordstream.com/social-media-marketing

http://www.qwaya.com/facebook-ads/facebook-ad-marketing-strategies-and-ti4ps

http://www.telegrafi.com/marketing/intro

http://www. pcworld. al/nielsen-mediat-sociale-marrin-pjesen-me-të-madhe-të-kohes-ne-ueb/ 
